\title{
Analysis of Fashion in Film and Television Works
}

\author{
Jiayi Jing ${ }^{1, *}$
}

\author{
${ }^{1}$ Yinchuan No.1 High School, Yinchuan, China, 750000 \\ *Corresponding author. Email: m15379516739@163.com
}

\begin{abstract}
The relationship between fashion styling and fashion trends in movies is complementary to each other. In Europe and the United States, the shows of major brands each season are closely related to the movies released each year. The Oscars, Cannes and other film awards also have "best costume award", which also proves that film and fashion are closely related. This paper analyses the influence of film clothing on fashion trends and brand shows from the perspectives of fashion becoming classic through film communication, the influence of film on fashion shows and the unique charm of fashion films. Film art is to reflect social reality or thoughts and feelings with fictional characters and plots, and it needs typical images to strike a chord with the audience. Clothing, as an important aspect of image building, is bound to become a special technique of expression in films. Clothing can express the characteristics of the time and the background of the story with the style of the outside. It can also express the psychological characteristics of characters and express the emotional basis with the colour meaning of the inside. In the same scene, costume changes can also be used to show the time and promote the development of the plot. So, costume is a very important aspect of filmmaking. This paper found that the development of film and television works can drive the spread of fashion to a large extent, and fashion is easier to be accepted by all kinds of people. Moreover, it can drive the trend to a certain extent, thus driving the development of economy. What is important about this study is that fashion is one of the most powerful means of visual influence, and fashion on film has always been an important signature device.
\end{abstract}

Keywords: fashion, film, film and television works, economics

\section{INTRODUCTION}

Life is like a play; a play is like life. Movies can be said to be a mirror in people's life. Through this mirror, people can not only peep and reflect on life, humanity and thought, but also can reflect from favoring to imitating, imitating the form of the person in the mirror. The author havs observed many fashion-related films and television works through watching films and television works of different times and discovered the influence of these works on fashion communication. Since the beginning of the 20th century, movies have been the most constant entertainment for the masses and the most effective distribution channel for new fashion trends. Fashion and film seem to be two art disciplines separated, but when movie stars spread new trends, they become connected in this symbiotic relationship, and their personal style influences the way they dress in movies. I watched many Audrey Hepburn movies and searched the Internet for many Givenchy dresses designed for Audrey Hepburn to complete my analysis by searching materials.According to the analysis, the fashion of film is a development process from unconscious display to intentional manufacturing, and it is also an analysis and discussion of the current film fashion. It is concluded that movies can show and spread fashion in real life on the one hand, on the other hand, they can create new fashion and new consumer hot spots in real life. In real life, disguised advertising of commercial and fashion products has a subtle effect on the audience, to achieve better economic goals. [1]

The research topic of this paper mainly focuses on the relationship between film and television works and fashion, the things film and television work bring to fashion communication. Film and fashion clothing have an inseparable relationship, film clothing has emerged at the historic moment. In different historical periods of the understanding of fashion, film clothing also has different characteristics.

\section{EXPLORE THE SPREAD OF FASHION FROM FILM AND TELEVISION WORKS}

With the booming development of movies, fashion 
has also been vigorously promoted, and movie stars have begun to show super strong fashion driving force and influence. Their clothes in the film have naturally become the highlights of the film, which can soon form a fashion trend and become popular style pursued by the general public.

\subsection{Audrey Hepburn and Givenchy}

Roman Holiday's image of Audrey Hepburn (the epitome of 1950s innocence) has influenced beauty for generations, and in fact in the 21st century she is still regarded as the epitome of innocent beauty. Breakfast at Tiffany's, the earliest film combining fashion and film, is the best example. The little black dress of Givenchy worn by Audrey Hepburn in the film not only embodies Audrey's elegant temperament, but also enriched her character image. She appeared in Breakfast at Tiffany's wearing a Givenchy black dress with a coffee cup in one hand and a croissant in the other. The little black dress soon joined Hepburn as a timeless monument in film history and one of fashion's most enduring classics. [2]. Audrey Hepburn, one of the most admired and emulated women, encouraged women to explore and emphasize their own advantages, which changed the way modern women dress and changed their self-cognition. Audrey Hepburn's first collaboration with Givenchy, whom she met on the set of Sabrina in these clothes, was a huge success and the start of a decades-long friendship [3,4]. Hepburn appeared in Sabrina in an evening dress, which made Givenchy a star at the time. Hepburn's elegance was perfectly matched by the dress, which could be said to have made her the queen of Hollywood fashion. In addition, Givenchy's costumes for Hepburn in Love in the afternoon, Funny Face and Charade proved time and again that fashion is most popular when it is combined with celebrities and film productions [5,6,7]. Born in 1927, Givenchy came from a privileged family that owned mines, so his family did not approve of his career in fashion. Instead, they expected him to become a lawyer. Fortunately, Givenchy was persistent enough to produce what followed. "He was Belle de Givenchy, the designer who put Paris on top of fashion," even Louis Vuitton's president admitted. Hepburn originally chose Balenciaga for her dress, but due to a time gap, Hepburn turned to Givenchy. Audrey Hepburn is undoubtedly the best spokesperson for the Givenchy brand.

Givenchy understood Hepburn's purity and elegance and became her image designer throughout her life. Hepburn became a brand ambassador for Givenchy, conveying the essence of its fashion design to the rest of the world. Hepburn is still remembered as an iconic figure in numerous films and photographs. Her beautiful silhouette perfectly interprets the delicacy and nobility of Givenchy fashion.
Thanks to Hepburn's perfect interpretation of Givenchy's fashion in the film, not only Did Givenchy create Hepburn, but she also presented Givenchy's fashion perfectly and played an important role in leading the fashion trend at that time. Up to now, nearly 50 years have passed. Most of the classic scenes of Hepburn wearing Givenchy costumes in the films are still in the minds of audiences. Not only did they set the trend at that time, but many people now know Givenchy from many of Hepburn's films.

Till today, when you open a fashion magazine, you will still see the phrase "If you do not know what to wear, a little black dress is the right thing to do". It is worth noting that this film not only created an enduring fashion style, but also created a classic fashion icon Audrey Hepburn. Her elegant, slender screen persona became an enduring symbol of an urban lady. Audrey Hepburn and Givenchy met in Sabrina, and the fashion world couldn't beat them. Today, the women of the world are still admiring Audrey Hepburn's fashion and falling for it.

\subsection{The DEVIL WEARS PRADA}

If you are even remotely interested in fashion, you are probably heard of this movie. The film is the first of its kind in a new century of fashion films, with big names and luxury goods everywhere. The film not only shows the glamour of the fashion circle, but also reveals the fragility and insecurity of people in the circle. The film satisfies people's imagination of the fashion editorial department, and the undercurrent behind the halo is turbulent, which makes fashion lovers excited.

While watching the movie, the author thought of many questions: what is the meaning of fashion? What does the status of a big brand mean? Is Prada's existence just to mark the status of the upper class? The movie told me the answer.

This movie can be said to be a fashion enlightenment for many people, including me. Even in 2021, this movie in 2006 can still serve as a template for many people to learn fashion. Thanks to the word "Prada" in the movie's title, searches for the fashion brand have increased along with the popularity of the movie. Even in life not everyone can afford expensive luxury goods, but because of the emergence of these movies, many people cannot afford luxuries such as Prada, but still can be like in the devil wears Prada to know about fashion, in the movie and film in some wear or some item, as the film's popularity, these clothes and items become the current trend. For ordinary people or stars who are rich enough to afford luxuries, they are more inclined to buy these products in order to pursue the trend, which can bring more economic and public opinion benefits to the brand. 
The film whether the workplace "unspoken rules" or gorgeous dress modelling, to today is still out of date, said it is the fashion film "top flow" is not too much. As can be seen from the statistics of Google, in June 2006, the same month when the Devil Wears Prada is released, the number of searches for Prada in Google reaches its peak in the middle of 2006 [8]. From this, movies still have a great influence on fashion. They can help brands better and more firmly establish brand awareness.

For a film, more is to give us its artistic and experiential sense. In a movie about fashion like this, fashion's point of view is the most worthy of our analysis. And, of course, it has its own core ideas about human nature and trying to find its way back into the film. In this film, we can see that fashion is to rely on picky survival, do not regard picky as the original sin of fashion. Successful people in the fashion industry, designers and magazine editors, are picky about detail, sometimes to the point of unbearable, but it is their profession that they have to do it.

Fashion is a very delicate and sensitive art, which is inseparable from the attention to detail.the film also told me some cruel facts of fashion. It is said in the movie that when people get old, their senses will gradually become dull, and they will not be able to bring the newer things. However, people constantly need the newer and more exciting things, so they will be eliminated sooner or later. That's the cruel thing about fashion. Everyone gets old, but fashion is always young. Besides that, in the movie, "devil" Miranda every successful in the magazine to promote a fashion product, behind are thousands of profits in the generation, if she hit the water, it represents the loss of the same profit; More importantly, fashion is the dominant trend, once you cannot dominate the trend, lose the accurate judgment of what is popular, you will be eliminated immediately, this is the cruelty of the fashion industry.

\subsection{Examples of films and television works that can make some items more popular}

Prada has a classic "Killer bag". The name "Killer" comes from Mission: Impossible 4, where Moreau wears a Prada Galleria, which is also the name of the bag [9].

The word "killer" itself is inaccurate, and it does not fully capture what makes the character and the bag special. The original English version uses the word "Assassin". Unlike the "killer", the "assassin" requires that the enemy should not be noticed before the action, and then suddenly kill the enemy in silence, so that the enemy is not aware of the death. So, in the film, Lea Seydoux's baby-faced assassin Moreau first approaches from a distance, carrying a Prada bag. Before the audience knew it, he abruptly pulled out a silenced pistol, sniped with precision, and then casually put the gun back in his pocket.

The contrast between the sweetness of the exterior and the ruthlessness of the real is far more striking than the violence of the exterior. That's one of the reasons why people were so impressed with this bag. Therefore, the characters in the movie and some plots can leave a deeper impression on people by matching certain clothes or items. The characters are the most useful weapons of fashion.

The Modesty of Galleria is achieved through clean lines and hidden decorative details, and there is not even a very large brand logo, which does not give people too much room to think. Also, because the lines are clean, very suitable for the assassin's crisp temperament. The line is cleaner, but the handle is just long enough to hang around your wrist, and the gold zipper makes it more feminine. Thus, for female assassins, the bag is not only quiet, but can even confuse the enemy. In the words of British VOGUE, she, like Lea Seydoux, the supporting actress who plays Moreau, is both feminine in appearance and tough enough to be the stuff of many women's dreams.

\section{CONCLUSION}

Film and fashion have some mutual influence, they are not two separate art disciplines, film and fashion are complementary. The completion of a film needs the support of fashion. No matter what era the film is in, it must be supported by fashion to achieve a high degree of completion, because in the historical change of nearly a century, fashion has evolved into one of the representatives of each era in different generations. Through clothing and fashion trends, people can make the film more appropriate to the historical background that the film wants to express. Many fashion products need movies to help them spread awareness. Film and television play an important role in the spread of fashion. It can not only spread information, but also play a vital role in the formation, development and evolution of culture. Melvin L. Defleur, an American scholar, once put forward the theory of cultural norms in his book Theory of Mass Communication to explain the influence of mass communication on social culture [10]. According to Defleur, by selectively providing information or highlighting certain issues, the mass media enables the audience to realize or know what values, beliefs and norms of behaviour are approved or recognized by the society, thus forcing the audience to act according to the recognized norms and take behaviours recognized by the social norms.

Through the above examples, the author found that film and television works can spread fashion and lead the fashion trend to a large extent. The success of film and television works can greatly enhance brand 
awareness and increase sales. Combining personality traits with fashion brands can greatly increase their appeal to people. The cultural value of these brands is also greatly reflected by the combination of characters and clothes. Through the study, we can understand the trend of the film circle and the fashion circle blend together and shine on each other. With the vigorous development of the film, fashion has been vigorously promoted. I also hope that in future driving works, we can see more extreme sensory experience brought by the fusion of fashion and film.

\section{AUTHORS' CONTRIBUTIONS}

This paper is independently completed by Jiayi Jing.

\section{ACKNOWLEDGMENTS}

I would like to show my deepest gratitude to my teachers and professor who helped me set up a good academic goal and taught me to master the basic research methods and structure of the paper.

\section{REFERENCES}

[1] Minjing Zhao and Zongyuan Liu. The orientation of film and television communication to fashion, 2019

[2] Blake Edwards. Breakfast at Tiffany's, 1961.

[3] Billy Wilder. Sabrina, 1954.

[4] Lixuan Shen. Clothing and fashion in film and television works, 2019

[5] Stanley Donen. Funny Face, 1957.

[6] Billy Wilder. Love in the afternoon, 1956.

[7] Stanley Donen. Charade, 1963.

[8] David Frankel. The Devil Wears Prada, 2006.

[9] Phillip Bradley Bird. Mission impossible 4, 2011.

[10] Melvin L. Defleur. The theory of culture norms in Theory of Mass Communication, 1966. 